\title{
Chemical compounds emitted by main components used in interior of vehicles
}

\author{
W. Librelon ${ }^{1}$, J. C. Souza ${ }^{2}$, V. F. C. Lins ${ }^{1 *}$ \\ ${ }^{1}$ Mechanical Engineering Graduate Program, Universidade Federal de Minas Gerais, Antonio Carlos Avenue 6627, \\ 30270901 Belo Horizonte, Brazil \\ ${ }^{2}$ Fiat Group, Contorno Avenue 3455, 32669-185 Betim, Brazil
}

Received 31 March 2018; accepted in revised form 10 July 2018

\begin{abstract}
Odors from materials used in new vehicles may cause satisfaction or dissatisfaction for people. This duality is due to a stimulation caused by receptors which act differently in each individual. It is already known that odors exhaling in a vehicles interior are caused by a gaseous mixture of the various materials which are volatilized, especially with the increase of internal temperature. The components of a newly manufactured automotive vehicles interior of high surface representativeness selected in this work are eight: air conditioner, ceiling liner, shelf package, rubber mats, door panel, carpet, instrument panel, and seats, which were analyzed by gas chromatography for the identification of volatile substances. The proportion of the peak area of each compound was calculated. Gas chromatography analysis identified the main substances from materials used in interior of vehicles which contribute to the new car odor: toluene, $p$-xylene, ethylbenzene or benzene derivatives, except in carcass of air conditioner. Polypropylene is a constituent of these components, except the rubber mats. Carbon disulfide appeared with a significant proportion of area in rubber mats and contributed in the formation of car odors.
\end{abstract}

Keywords: material testing, automobile, volatile substances, chromatography, industrial applications

\section{Introduction}

Polymeric materials are used in automobile manufacturing mainly because of low specific weight $[1,2]$. The automobile interior is a complex thermal environment which continually varies during travelling on roads [3]. Wu et al. [3] reported that panel interior temperature increases as driving velocity increases in the evening, while the interior temperature decreases as driving velocity increases during daytime. The maximum value of automobile interior temperature registered by $\mathrm{Wu}$ et al. [3] was near to $46^{\circ} \mathrm{C}$. The volatile substances from polymers used in vehicles interior can generate odors of varying intensities and duration which may or may not please people.

Literature reports studies about the chemical analysis of the air in interior of vehicles but studies about the chemical analysis of vehicle components are scarce.
Yoshida [4] analyzed organic compounds in the interior air of 101 different types of Japanese domestically produced private-use cars. Chien [5] investigated inter-brand, intra-brand and intra-model variations in volatile organic compounds (VOC) levels inside new cars and found that the intra-model variability (mean, 47\%) in the VOC levels was approximately $50 \%$ that within each brand (mean, 95\%). The effect of temperature on interior VOC levels was examined using model automobiles with and without the air-conditioning running [5]. VOCs have negative impacts on human health (primarily neurological), cancer (such as leukemia), neurobehavioral effects and adverse effects on the kidney [6]. Geiss [7] investigated the presence of selected volatile organic compounds (VOCs) including aromatic, aliphatic compounds and low molecular weight carbonyls in

"Corresponding author, e-mail: vlins@deq.ufmg.br

(C) BME-PT 
the interior of 23 used private cars during summer and winter. VOC concentrations often exceeded levels typically found in residential indoor air, e.g. benzene concentrations reached values of up to $149.1 \mu \mathrm{g} \cdot \mathrm{m}^{-3}$. Overall VOC concentrations were $40 \%$ higher in summer, with temperatures inside the cars reaching up to $70^{\circ} \mathrm{C}$ [7]. Faber et al. [8] examined the indoor air composition inside the cabins of five new vehicles and concluded about the influence of the materials used. Bradzik et al. [9] determined if analysis of air samples collected from an unconditioned car cabin can be used as a quality control measure. To analyze the influencing factors of in-car VOCS pollution concentrations, 38 taxis were investigated by Chen et al. [10] on the static and closed conditions. Lu et al. [11] identify and quantify the levels of volatile organic compounds (VOCs) and carbonyl compounds (CCs) in air samples collected from the cabins of newly produced, medium- and large-size coaches in China.

$\mathrm{Xu}$ et al. [12] published a review of the air quality of motor vehicle cabin microenvironment concluding that air recirculation with high-efficiency air filter was the most effective measure to lower air pollutant concentrations. The in-cabin pollutant concentrations are often high for newly manufactured cars, at high interior temperatures, or with low air exchange rate [12].

Literature reports the concern of researchers to develop materials for application in car interior that produce emission of low intensity of odors as the low odor-emissive polylactide/cellulose fiber biocomposites [13].

The objective of this research is to identify the compounds which can be released by materials used in vehicles and which constitute the odor of the new car, by using headspace solid phase micro extraction gas chromatographic analysis combined with mass spectrometry. A preliminary study organized the relation of components of automotive interiors and classified in two groups: high representativeness and low representativeness. Components with a higher representativeness were the materials with a higher surface area in the interior of vehicles. In this work, the chromatographic results of components with high representativeness were presented and discussed.

\section{Experimental section}

A previous study for the methodology selection and parameter optimization was performed [14-16]. The headspace solid phase micro extraction gas chromatographic analysis was performed on a Clarin 680 Perkin Elmer brand chromatograph coupled with a Clarus SQ 8T mass spectrometer, (both Perkin Elmer Instruments, Waltham, United States). Chromatographic conditions were: $30 \mathrm{~m}$ long WCOT HP-5 chromatographic column considering a flow rate of $5 \mathrm{~mL} / \mathrm{min}$ for the entrainment gas, $0.25 \mathrm{~mm} \mathrm{ID,}$ $0.25 \mu \mathrm{m}$ film thickness, an inlet pressure of $72.4 \mathrm{kN} / \mathrm{m}^{2}$, an auxiliary pressure of $69.0 \mathrm{kN} / \mathrm{m}^{2}$, a heating ramp starting at $40^{\circ} \mathrm{C}$ at a rate of $6^{\circ} \mathrm{C} / \mathrm{min}$ to $150^{\circ} \mathrm{C}$, final stage with a rate of $10^{\circ} / \mathrm{min}$ up to $180^{\circ} \mathrm{C}$ and total time of 21 minutes. The mass spectrometer used the electron ionization mode in a wide range of $45-300 \mathrm{~m} / \mathrm{z}$, with a reading start time of 1 minute.

The cars under investigation were new and analyzed at the factory. The components of vehicle under study were produced by industries near the automobile assembly plant located in Betim, Brazil, 19 $58^{\prime} 04^{\prime \prime}$ S latitude, $44^{\circ} 11^{\prime} 54^{\prime \prime} \mathrm{W}$ longitude. The temperature of the interior of vehicles is $24 \pm 2{ }^{\circ} \mathrm{C}$. Air condition was in off condition. Three samples of each material were analyzed. Samples were obtained from the removal of fragments in different parts of each type of material in each component totaling a mass of $300 \pm 10 \mathrm{mg}$. Table 1 shows the list of components analyzed in this work. Each sample was conditioned in glass vials with $10 \mathrm{~mL}$ capacity and maintained at a temperature of $20^{\circ} \mathrm{C}$ before analyses were performed. The conditioning time before analysis was 24 hours. The time of the chromatographic run was 21 minutes. However, the headspace incubation time was 1 hour. The method for the headspace was: syringe with capacity of $2.5 \mathrm{~mL}$ and temperature of $110^{\circ} \mathrm{C}$, filling speed of $100 \mu \mathrm{L} / \mathrm{s}$, sample volume of $1 \mathrm{~mL}$, incubation temperature of $100^{\circ} \mathrm{C}$, stirring speed of $500 \mathrm{rpm}$, stirring time of $30 \mathrm{~s}$ and stopping time between each shaking of $30 \mathrm{~s}$. The identification of the main substances, based on their peak integration, was performed by using the equipment software, which has a database based on the National Institute of Standards and Technology (NIST).

\section{Results and discussion}

The components of vehicles interior of high representativeness selected in this work are: air conditioner, ceiling liner, shelf package, carpet, door panel, rubber mats, instrument panel, and seats. The materials of these components were analyzed using chromatographic analysis. 
Table 1. Selected materials of components used in the interior of vehicles.

\begin{tabular}{|l|l|l|c|c|}
\hline \multicolumn{1}{|c|}{ Component } & \multicolumn{1}{|c|}{ Description } & \multicolumn{1}{c|}{ Material } & $\begin{array}{c}\text { Sample volume } \\
{[\mathbf{m L}]}\end{array}$ & $\begin{array}{c}\text { Surface area } \\
{\left[\mathbf{m m}^{2}\right]}\end{array}$ \\
\hline Air conditioner & Carcass & Polypropylene & 5 & 1350 \\
\hline Ceiling lining & Ceiling lining & Cloth + Polypropylene + Polyurethane & 7 & 1450 \\
\hline Shelf package & Shelf package & Polypropylene + Wood & 6 & 1440 \\
\hline Carpet & Carpet & $\begin{array}{l}\text { Expandable Polystyrene + Shredded denim + } \\
\text { Thermoplastic + Polypropylene + Polystyrene }\end{array}$ & 7 & 1420 \\
\hline Door panel & Polymer & Polypropylene & 5 & 1340 \\
\hline Rubber Mats & Rubber Mats & Natural Rubber + Recycled Tire & 4 & 1300 \\
\hline Instrument panel & Instrument panel & Polypropylene & 5 & 1360 \\
\hline Leather seats & Synthetic leather & Polyurethane & 8 & 1400 \\
\hline
\end{tabular}

The air conditioner contains nine materials: pipe cover, composite foam, adhesive foam, buttons, hose, carcass, rotor, foam, and straws. Table 2 shows results of chromatography of carcass (Figure 1) which has the largest exposed area inside the vehicle. The air conditioner is an important component as the air circulation passes through the materials carrying the odors into the interior of vehicle. The main compound found was 2,3,3,4-tetramethyl cyclobutanone. Cyclobutanones, identified in irradiated food, promote cancer development and cause genetic damage in rats [17].
Table 3 presents the substances identified in the ceiling liner component and, according to the calculations of the proportion of the areas of the chromatographic peaks, toluene, ethylbenzene and $p$-xylene are the substances that stand out and have the highest relative proportions. Chromatogram of ceiling liner material is shown in Figure 2. All substances in this component have odorant characteristics. With this, and still being a component with great representation in the interior of vehicles, containing a large surface area, deserves special attention. It is noteworthy that the three substances featured in the area have odorant

Table 2. Results of chromatography of carcass of air conditioner.

\begin{tabular}{|l|c|c|c|l|}
\hline \multicolumn{1}{|c|}{ Substance } & Area & $\mathbf{\%}^{\prime}$ & $\boldsymbol{M}_{\mathbf{w}}$ & CAS number \\
\hline 1-bromo, 2-methyl, 2-propanol & 21560 & 13 & 153019 & $38254-49-8$ \\
\hline 1,1'-oxibisheptane & 16325 & 10 & 214387 & $629-64-1$ \\
\hline 3-ethyl, 3-methylheptadecane & 12263 & 7 & 282556 & 11536486 \\
\hline 2,3,3,4-tetramethyl cyclobutanone & 44389 & 26 & 126196 & $53907-63-2$ \\
\hline 4,5-dimethylnonane & 13328 & 8 & 156308 & $17302-23-7$ \\
\hline
\end{tabular}

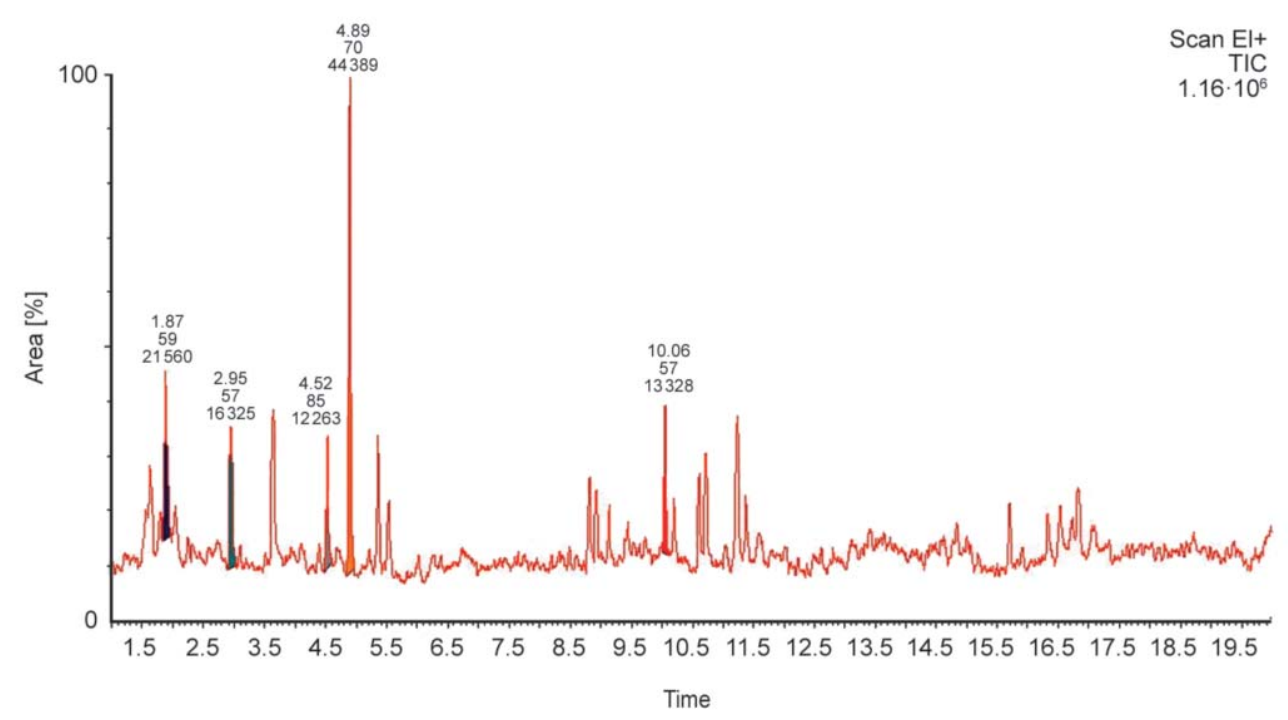

Figure 1. Chromatogram of carcass of air conditioner. 
Table 3. Chromatographic analysis of ceiling lining.

\begin{tabular}{|l|c|c|c|l|}
\hline \multicolumn{1}{|c|}{ Substance } & Area & \% & $\boldsymbol{M}_{\mathbf{w}}$ & \multicolumn{1}{c|}{ CAS number } \\
\hline Propylhexedrine & 82048 & 3.07 & 155280 & $101-40-6$ \\
\hline Toluene & 379040 & 14.20 & 92138 & $108-88-3$ \\
\hline Ethylbenzene & 325384 & 12.19 & 1061650 & $100-41-4$ \\
\hline$p$-xylene & 780868 & 29.24 & 106165 & $106-42-3$ \\
\hline 1-ethyl, 2-methylbenzene & 209035 & 7.83 & 120190 & $611-14-3$ \\
\hline Propylbenzene & 34718 & 1.30 & 120190 & $103-65-1$ \\
\hline 1-ethyl-4-methylbenzene & 121867 & 4.56 & 370527 & $65104-04-3$ \\
\hline 1-ethyl-2-methylbenzene & 107295 & 4.02 & 120190 & $611-14-3$ \\
\hline $1,2,3$-trimethylbenzene & 22235 & 0.83 & 160216 & $73905-55-3$ \\
\hline $1,2,4-$ trimethylbenzene & 173544 & 6.50 & 252220 & $95-63-6$ \\
\hline
\end{tabular}

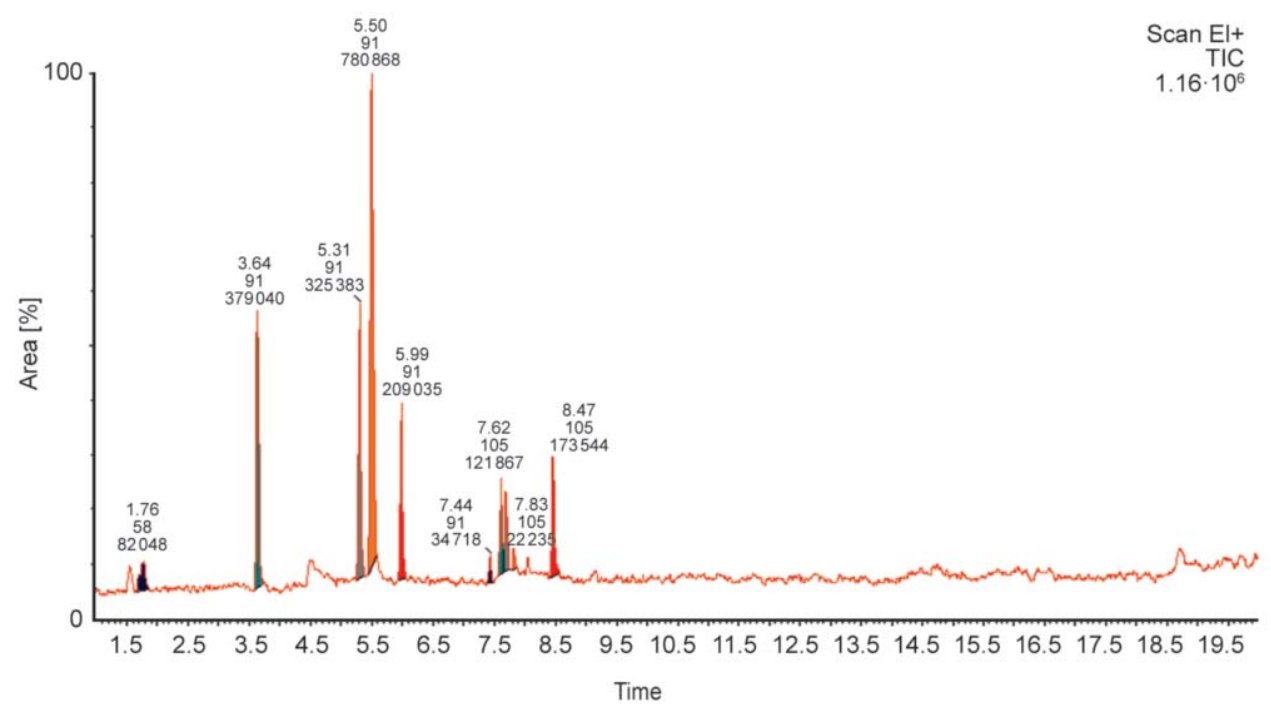

Figure 2. Chromatogram of ceiling liner.

characteristics of pleasantness. Among the analyzed materials, the presence of toluene, a volatile organic compound (VOC) must be emphasized. Mono-aromatic hydrocarbons such as benzene, toluene and xylene, compounds found in this study, are known to be toxic [18-21]. Toluene, ethylbenzene, xylene, formaldehyde, acetaldehyde, acrolein/acetone, and isovaleraldehyde were relatively abundant in the cabins of coaches in China as reported by Lu et al. [11]. Brodzik et al. [9] measured the in-cabin pollutant compositions in several unconditioned, newly produced cars. Depending on the vehicle, the concentration of aromatic hydrocarbons varied from $12 \%$ to $27 \%$ of total VOCs [9]. The very short period between car production and sampling of the in-vehicle air permits the assumption that the entire TVOC (total VOCs) originates from off-gassing of interior materials [9]. Brodzik et al. [9] also concluded that the presence of a sunroof could increase the in-cabin concentrations of aliphatic hydrocarbons due to emissions from sealing materials and adhesives around the sunroof. The intentional misuse of volatile solvents, such as toluene, is a persistent public health concern. Limited clinical data suggest that chronic inhalant abusers may experience signs of withdrawal, including anxiety [22]. Propylhexedrine [23], found among compounds emitted by ceiling lining, is a cycloalkylamine that is structurally similar to methamphetamine and causes release of dopamine, and noradrenaline from presynaptic vesicles.

The shelf package is a component made from a composite of polypropylene with wood fiber. According to Table 4, the 3-carene was the substance found in a major proportion in shelf package. 3-carene is a constituent of trepentine that is obtained from the distillation of the resin of coniferous species, according to Corredor and Sarria Villa [24]. With the highest proportion of peak area (Table 4), the 3-carene represents the main substance and is justified using the wood fiber in the shelf package. With a sweet and intense characteristic, 3-carene can be considered a material that participates in a significant way 
Table 4. Results of chromatography analysis of materials of shelf package.

\begin{tabular}{|l|r|r|r|l|}
\hline \multicolumn{1}{|c|}{ Substance } & Area & \% & \multicolumn{1}{c|}{$\boldsymbol{M}_{\mathbf{w}}$} & CAS number \\
\hline Propylhexedrine & 129365 & 8.29 & 155280 & $101-40-6$ \\
\hline Chlorphenamine & 61292 & 3.93 & 274789 & $113-92-8$ \\
\hline Toluene & 149186 & 9.56 & 92138 & $108-88-3$ \\
\hline Ethylbenzene & 38176 & 2.45 & 106165 & $100-41-4$ \\
\hline$p$-xylene & 112041 & 7.18 & 106165 & $106-42-3$ \\
\hline$m$-xylene & 29222 & 1.87 & 106168 & $108-38-3$ \\
\hline 3-carene & 162971 & 10.45 & 136238 & $13466-78-9$ \\
\hline 1-methylene-4-(1-methylethenyl)cyclohexane & 37814 & 2.42 & 136234 & $499-97-8$ \\
\hline 2-pentylfuran & 30186 & 1.93 & 138206 & $3777-69-3$ \\
\hline 1,2,4-trimethylbenzene & 20341 & 1.30 & 252220 & $95-63-6$ \\
\hline 2,6,10,15-trimethylheptadecane & 90433 & 5.80 & 296574 & $54833-48-6$ \\
\hline Triacontane & 35401 & 2.27 & 422183 & $638-68-6$ \\
\hline 2,6,10,15-tetramethylheptadecane & 106850 & 6.85 & 296574 & $54833-48-6$ \\
\hline 2,6,10-trimethyldodecane & 46030 & 2.95 & 212414 & $3891-98-3$ \\
\hline Tritetracontane & 103051 & 6.60 & 605158 & $7098-21-7$ \\
\hline
\end{tabular}

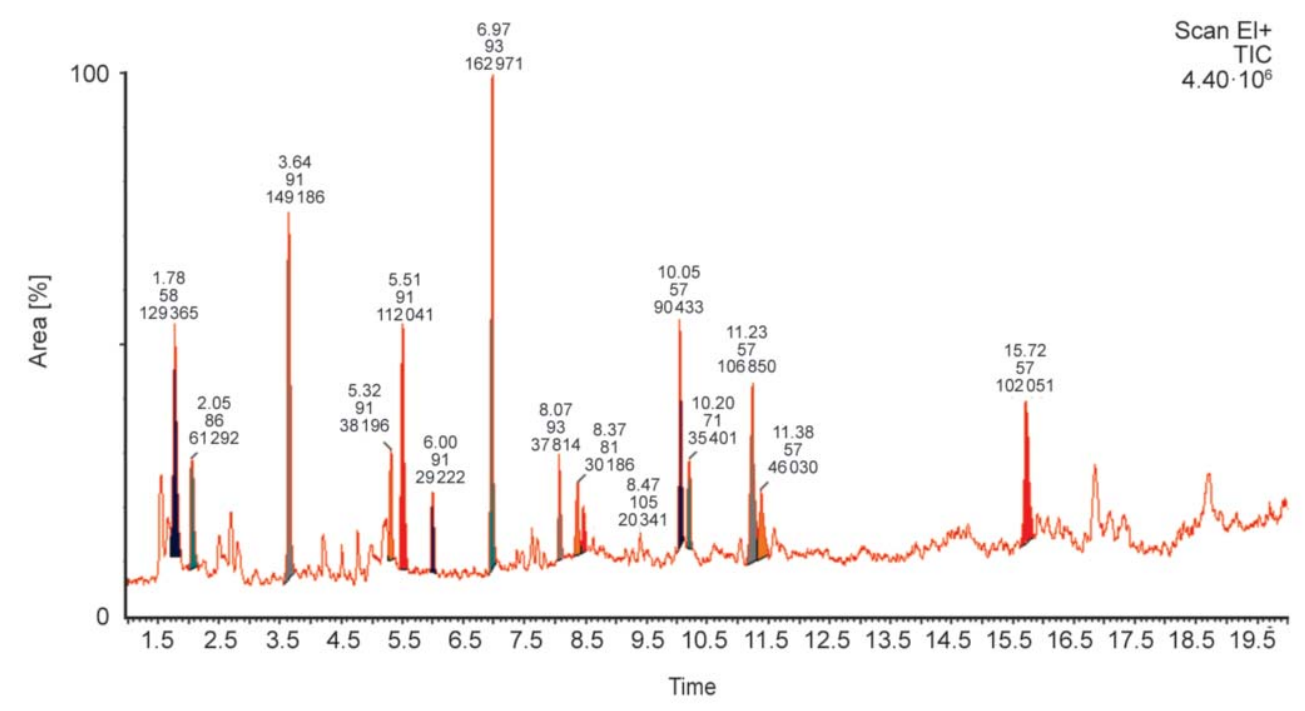

Figure 3. Chromatogram of shelf package.

in the formation of the odor. Toluene, $\mathrm{p}$-xylene, and propylhexedrine are the other outstanding substances emitted from polypropylene. Heptadecane, $\mathrm{C}_{17} \mathrm{H}_{36}$, a solid at standard conditions and tritetracontane, $\mathrm{C}_{43} \mathrm{H}_{88}$, an alkane with a greater number of carbons were other substances present in high proportions. It is worth mentioning that chlorphenamine, found in the shelf package, is an anti-histamine drug [25]. Figure 3 presents the chromatogram of shelf package.

Carpet is a prominent component as it has a large surface area and thus contributes in a more representative way to the formation of the internal odors of the vehicle. Table 5 presents the substances identified by using chromatographic analysis (Figure 4) of carpet and demonstrates the marked presence of toluene, $p$-xylene and hentriacontane with the largest representations of area of chromatographic peaks. Despite a significant proportion of $11.32 \%$, hentriacontane is not important in the formation of odors. Hentriacontane also called untriacontane, is a solid, long-chain alkane hydrocarbon with the structural formula $\mathrm{CH}_{3}\left(\mathrm{CH}_{2}\right)_{29} \mathrm{CH}_{3}$ [23]. It is found in a variety of plants, including peas (pisum sativum), gum arabic (acacia senegal) and others [26].

With this, only toluene and $p$-xylene are outstanding. But it should be noted that ethylbenzene, which despite a small proportion, is a substance that can interfere negatively in the formation of odors. Jiang et al. [27] reported therapeutic effects of isothiocyanate which was found in carpet of newly manufactured automobiles. 
Table 5. Results of chromatographic analysis of materials of carpet.

\begin{tabular}{|l|c|c|l|l|}
\hline \multicolumn{1}{|c|}{ Substance } & Arae & $\mathbf{\%}^{\prime}$ & \multicolumn{1}{c|}{$\boldsymbol{M}_{\mathbf{w}}$} & \multicolumn{1}{c|}{ CAS number } \\
\hline Propylhexedrine & 37365 & 7.06 & 155280 & $101-40-6$ \\
\hline 1,1'-oxibisheptane & 18080 & 3.41 & 214387 & $629-64-1$ \\
\hline Toluene & 97923 & 18.49 & 92138 & $108-88-3$ \\
\hline Methyl, 2-methyl, 2-methoxy, 3-hidroxyindan-1-one-3-carboxilate & 28520 & 5.39 & 126153 & $32774-63-3$ \\
\hline 3,5-dimethylheptane & 18852 & 3.56 & 128255 & $926-82-9$ \\
\hline Ethylbenzene & 30998 & 5.85 & 106165 & $100-41-4$ \\
\hline$p$-xylene & 99194 & 18.73 & 106165 & $106-42-3$ \\
\hline 1,3-dimethylbenzene & 27607 & 5.21 & 106168 & $108-38-3$ \\
\hline 1,2,4-trimethylbenzene & 20201 & 3.81 & 252220 & $95-63-6$ \\
\hline Isothiocyanatecyclohexane & 21741 & 4.11 & 141234 & $1122-82-3$ \\
\hline 1-fluorododecane & 12635 & 2.39 & 188325 & $334-68-9$ \\
\hline Hentriacontane & 59927 & 11.32 & 605158 & $7098-21-7$ \\
\hline Hexacosyl acetate & 21674 & 4.09 & 424743 & $822-32-2$ \\
\hline
\end{tabular}

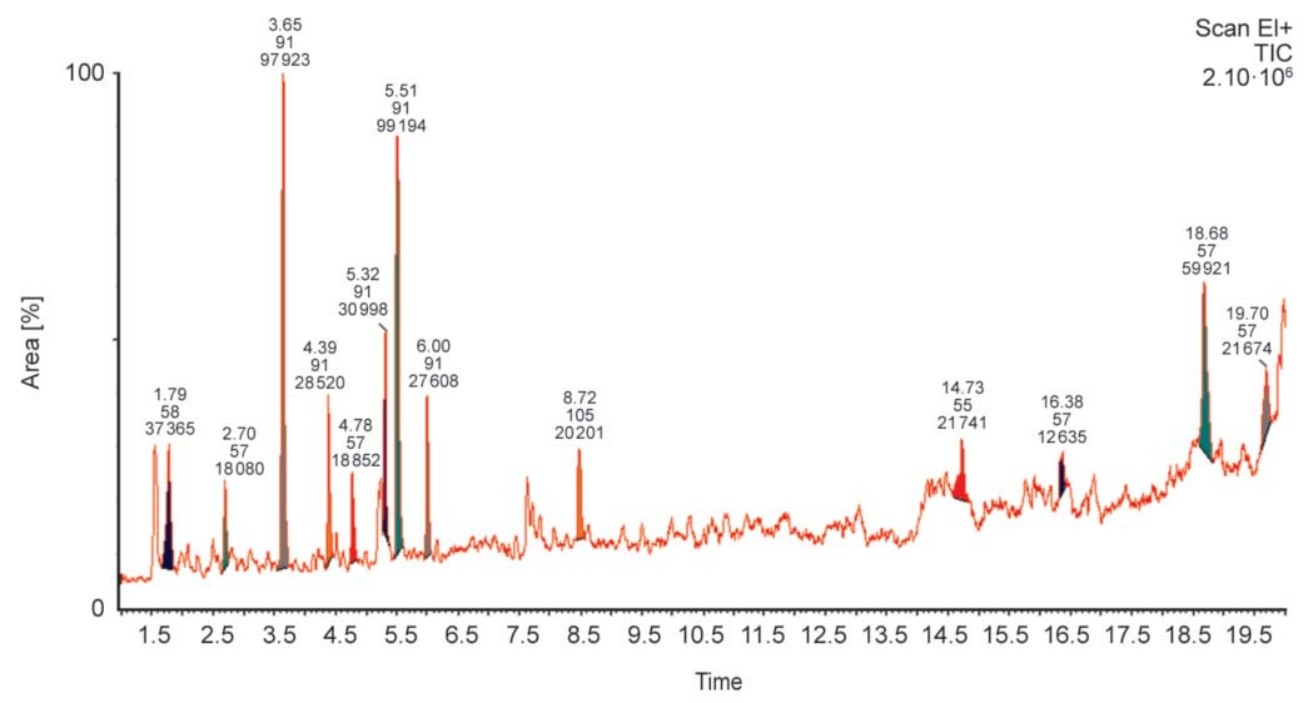

Figure 4. Chromatogram of carpet.

Of all the materials contained in the door panels such as polypropylene, polystyrene, cloth and screen, the analyzed polypropylene has significant representativeness. Table 6 presents the chromatographic analysis of door panel (polypropylene), and Figure 5 shows the chromatogram of door panel. The emitted $p$-xylene has a significant peak area and is an odor-generating substance. Other substances such as hentriacontane and tritetracontane, which also have higher peak areas, do not represent importance in the formation of odors. Hentriacontane, has various pharmacological effects including anti-inflammatory, antitumor and antimicrobial activities [26].

With high representativeness in the composition of the interior of vehicles, rubber mats deserve greater attention, especially for the highlight in the peak of carbon disulfide, as shown in Table 7. The chromatogram of rubber mats is shown in Figure 6.With a characteristic odor of ether, carbon disulfide participates in a significant way in the formation of odor of the interior of vehicles. Carbon disulfide $\left(\mathrm{CS}_{2}\right)$ is used in industry. Disulfide and (polysulfide) bonds are the crosslinking groups that result from the vulcanization of rubber; it has been shown to have neurotoxic effects [28]. $P$-xylene comes in second in the proportion of area, but much smaller than carbon disulfide. The other substances are not representative considering the area proportions.

Table 8 shows the substances identified in the instrument panel, and Figure 7 shows the chromatogram of instrument panel. As instrument panel has a large surface area, the instrument panel can contribute to the formation of odor releasing toluene and $p$-xylene, although they have little representativeness in the peak area ratio. 
Table 6. Chromatographic analysis of door panel (polypropylene).

\begin{tabular}{|l|c|c|c|l|}
\hline \multicolumn{1}{|c|}{ Substance } & Area & $\boldsymbol{\%}^{\prime}$ & $\boldsymbol{M}_{\mathbf{w}}$ & CAS number \\
\hline Toluene & 66485 & 2.26 & 92138 & \multicolumn{1}{l|}{$108-88-3$} \\
\hline 2-ethylbutyl isobutyl carbonate & 10512 & 0.36 & 202294 & 91698429 \\
\hline 2-ethylhexyl ester pentanoic acid & 123556 & 4.19 & 214344 & $5451-87-6$ \\
\hline 1-fluorododecane & 29675 & 1.01 & 188325 & $334-68-9$ \\
\hline 4,5-dimethylnonane & 94726 & 3.21 & 156308 & $17302-23-7$ \\
\hline$p$-xylene & 60791 & 2.06 & 106165 & $106-42-3$ \\
\hline 1-ethyl, 2-methylbenzene & 20911 & 0.71 & 120190 & $611-14-3$ \\
\hline 4-nitrophenyl 3-phenylpropanoate & 58453 & 1.98 & 271272 & 562076 \\
\hline 1,2,4-trimethylbenzene & 14950 & 0.51 & 252220 & $95-63-6$ \\
\hline Butyl nonyl sulfite & 50427 & 1.71 & 264425 & 4926348 \\
\hline Hentriacontane & 625914 & 21.23 & 605158 & $7098-21-7$ \\
\hline Triacontane & 146946 & 4.98 & 422183 & $638-68-6$ \\
\hline 6-ethyl-3-octanyl isobutyl oxalate ester & 46636 & 1.58 & 286407 & 4926362 \\
\hline 2,6,10,15-tetramethylheptadecane- & 290162 & 9.84 & 296574 & $54833-48-6$ \\
\hline 2,6,10-trimethyldodecane & 127057 & 4.31 & 212414 & $3891-98-3$ \\
\hline Tritetracontane & 357412 & 12.12 & 605158 & $7098-21-7$ \\
\hline Heneicosane & 100000 & 3.39 & 296574 & $629-94-7$ \\
\hline 3,5,24-trimethyltetracontane & 84536 & 2.87 & 605177 & $55162-61-3$ \\
\hline
\end{tabular}

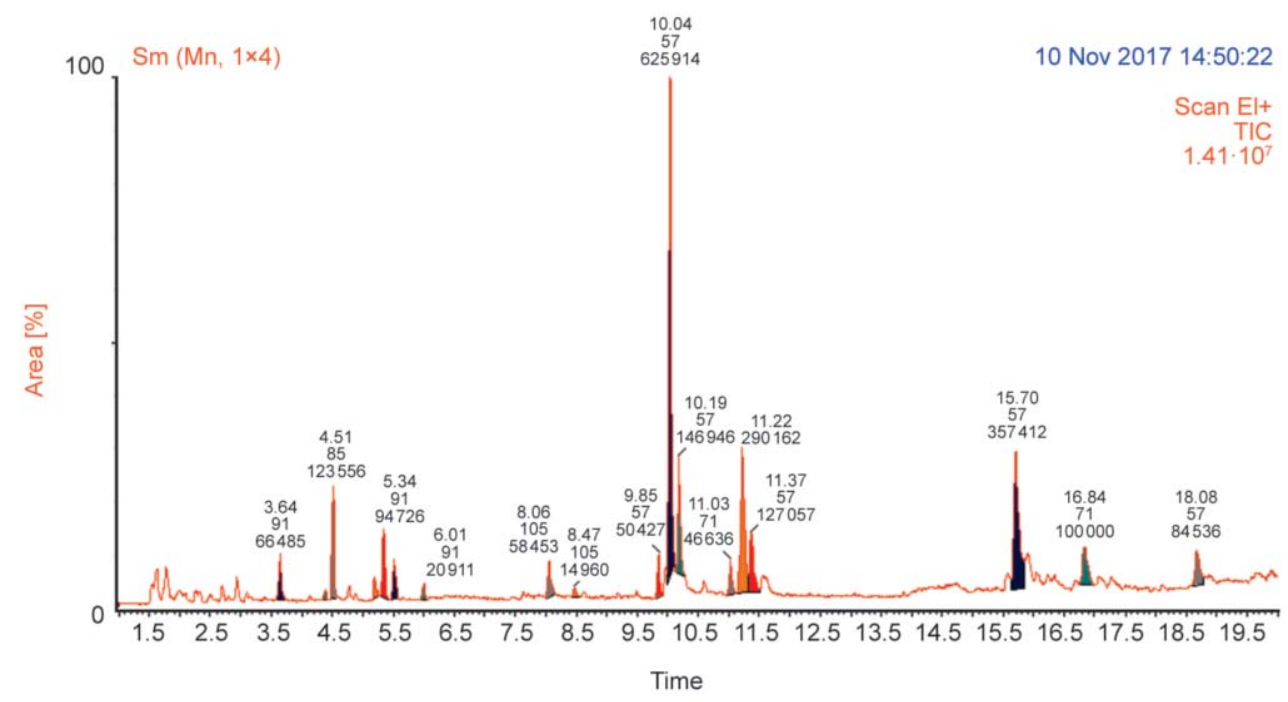

Figure 5. Chromatogram of door panel.

Seats have high representativeness, and the synthetic leather occupies a large surface area. Toluene and $p$-xylene were the substances of greatest proportions of peak area. Table 9 presents the substances identified in the seat with their percentage ratio of area of chromatographic peaks, and Figure 8 shows the chromatogram of leather seats.

Toluene and $p$-xylene were found after chromatographic analysis of ceiling lining (Table 3 ), shelf package (Table 4), carpet (Table 5), door panel (Table 6), rubber mats (Table 7), instrument panel (Table 8), and synthetic leather seats (Table 9). Polypropylene is a constituent of ceiling lining, shelf package, carpet, door panel, and instrument panel. The use of additives is a common way to modify polypropylene fibers to improve their properties [29]. Usually, additives such as organic pigments or flame retardants are incorporated into the polymer by physical means during fiber formation, for example [29]. Organic pigments added in polypropylene as quinacridone and phthalocyanine contain aromatic rings and thus can produce compounds such as toluene and $p$-xylene [29]. 
Table 7. Chromatographic analysis of rubber mats.

\begin{tabular}{|c|c|c|c|c|}
\hline Substance & Area & $\%$ & $M_{\mathrm{w}}$ & CAS number \\
\hline Trisylane & 124615 & 5.11 & 92320 & $7783-26-8$ \\
\hline Carbon disulfide & 1147204 & 47.06 & 76141 & $75-15-0$ \\
\hline 2-cyclopenten-1-one & 39944 & 1.64 & 82100 & $930-30-3$ \\
\hline Etilefrin-propionyl & 37966 & 1.56 & 349427 & 547106 \\
\hline Toluene & 42123 & 1.73 & 92138 & $108-88-3$ \\
\hline Ethylbenzene & 37669 & 1.55 & 106165 & $100-41-4$ \\
\hline$p$-xylene & 163290 & 6.70 & 106165 & $106-42-3$ \\
\hline 1-ethyl, 2-methylbenzene & 65296 & 2.68 & 120190 & $611-14-3$ \\
\hline 1-ethyl-4-methylbenzene & 21572 & 0.88 & 370527 & 65104-04-3 \\
\hline 1,2,3-trimethylbenzene & 24528 & 1.01 & 160216 & $73905-55-3$ \\
\hline 1,2,4-trimethylbenzene & 11820 & 0.48 & 252220 & $95-63-6$ \\
\hline 4-nitrophenyl- $\beta$-phenyl propionate & 12953 & 0.53 & 271268 & $17895-71-5$ \\
\hline 1,2,4-trimethylbenzene & 55304 & 2.27 & 252220 & $95-63-6$ \\
\hline
\end{tabular}

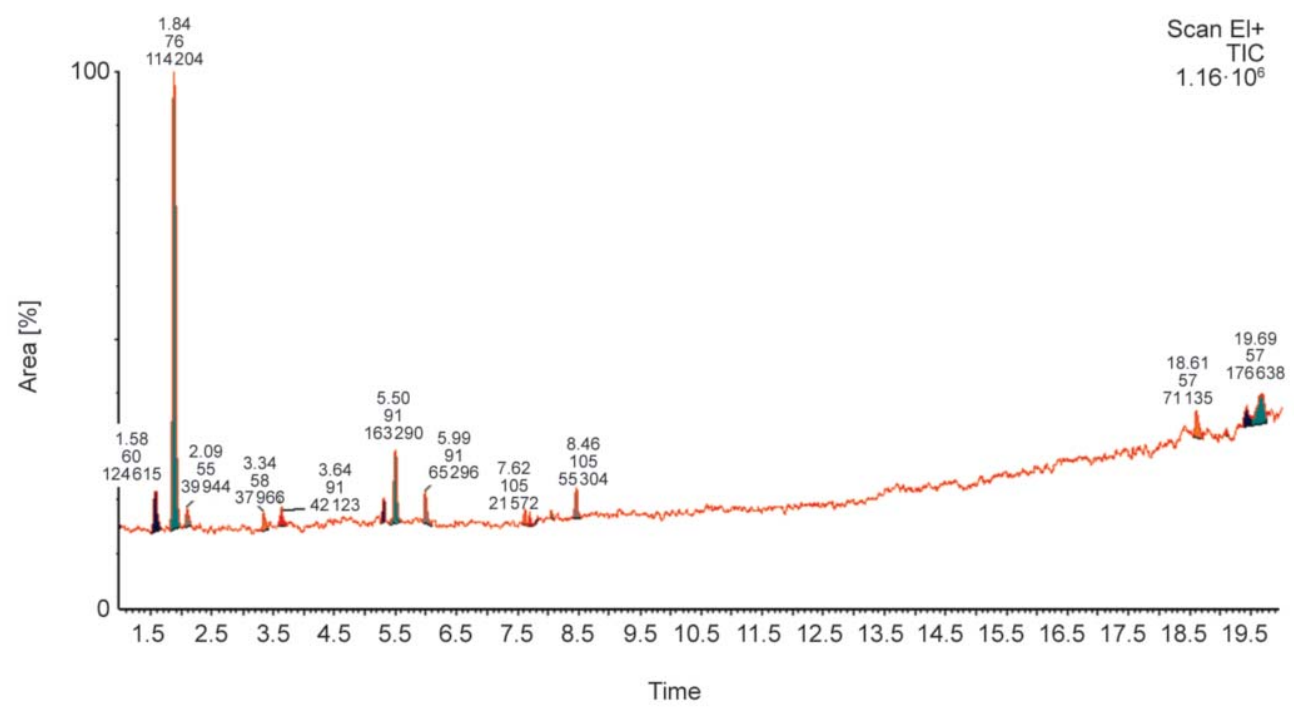

Figure 6. Chromatogram of rubber mats.

Table 8. Chromatography results of materials of instrument panel.

\begin{tabular}{|l|c|c|c|l|}
\hline \multicolumn{1}{|c|}{ Substance } & Area & $\mathbf{o}^{\prime}$ & $\boldsymbol{M}_{\mathbf{w}}$ & \multicolumn{1}{c|}{ CAS number } \\
\hline 1,1'-oxybisheptane & 50988 & 2.06 & 214387 & $629-64-1$ \\
\hline Toluene & 80997 & 3.26 & 92138 & $108-88-3$ \\
\hline 3-etyl, 3-methylheptadecane & 47191 & 1.90 & 282556 & 11536486 \\
\hline$p$-xylene & 58242 & 2.35 & 106165 & $106-42-3$ \\
\hline 1-ethyl, 2-methylbenzene & 14002 & 0.56 & 120190 & $611-14-3$ \\
\hline 1,2,4-trimethylbenzene & 12007 & 0.48 & 252220 & $95-63-6$ \\
\hline 2,6,10,15-tetramethylheptadecane & 478762 & 19.30 & 296574 & $54833-48-6$ \\
\hline 2-ethylhexyl tridecyl sulfite & 106411 & 4.29 & 376640 & 6740778 \\
\hline 2,6,10,15-tetramethylheptadecane & 252470 & 10.18 & 296574 & $54833-48-6$ \\
\hline 3,8-dimethyldecane & 94610 & 3.81 & 170334 & $17312-55-9$ \\
\hline Tritetracontane & 450048 & 18.14 & 605158 & $7098-21-7$ \\
\hline Heneicosane & 257686 & 10.39 & 296574 & $629-94-7$ \\
\hline
\end{tabular}

\section{Conclusions}

The components of vehicles interior of high representativeness due to the higher exposed area selected in this work are: air conditioner, ceiling liner, shelf package, rubber mats, door panel, carpet, instrument panel, and seats. The materials of the selected components were analyzed by using chromatographic analysis. 


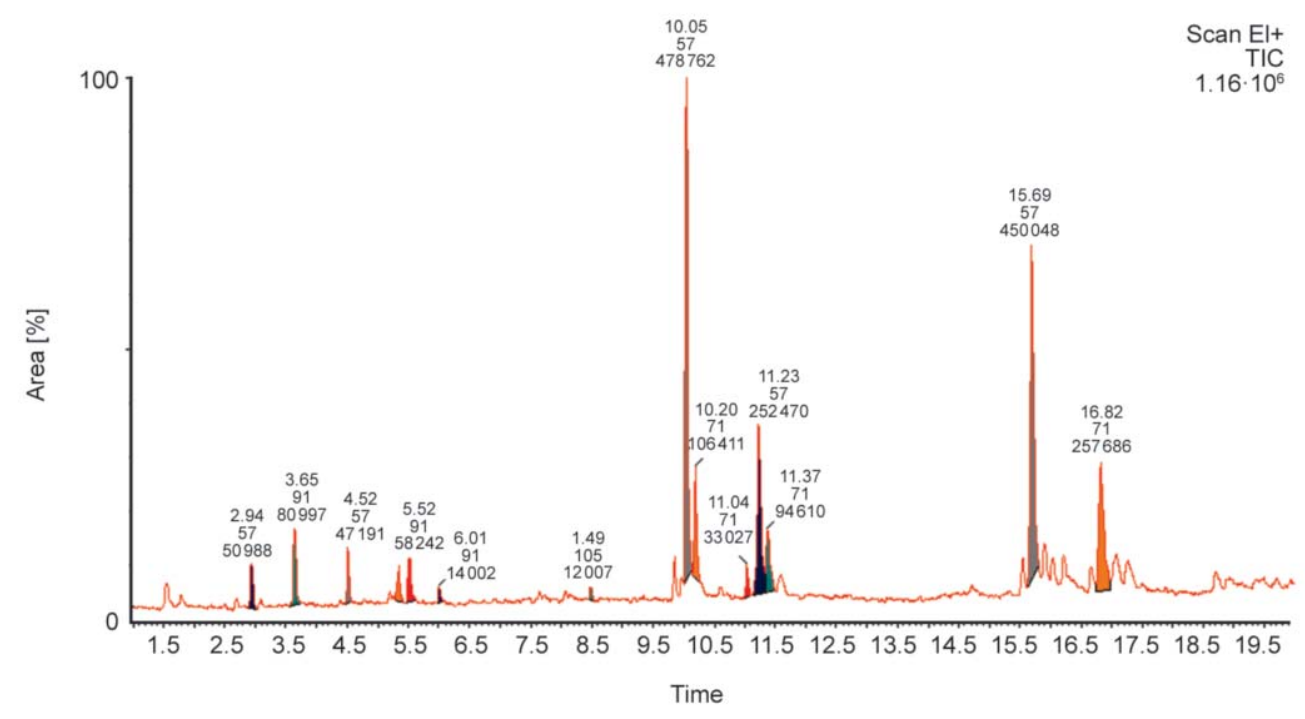

Figure 7. Chromatogram of instrument panel.

Table 9. Chromatographic analysis of leather seat (synthetic leather).

\begin{tabular}{|l|r|r|r|l|}
\hline \multicolumn{1}{|c|}{ Substance } & Area & $\mathbf{\%}$ & $\boldsymbol{M}_{\mathbf{w}}$ & CAS number \\
\hline$N, N^{\prime}$-dimethyl- $N, N^{\prime}$-dinitroethanediamide & 147808 & 19.48 & 206114 & $14760-99-7$ \\
\hline Toluene & 163991 & 21.61 & 92138 & $108-88-3$ \\
\hline Ethylbenzene & 30114 & 3.97 & 106165 & $100-41-4$ \\
\hline$p$-xylene & 113578 & 14.97 & 106165 & $106-42-3$ \\
\hline 1-ethyl, 2-methylbenzene & 41864 & 5.52 & 120190 & $611-14-3$ \\
\hline 1,2,4-trimethylbenzene & 24492 & 3.23 & 252220 & $95-63-6$ \\
\hline 3,5,24-trimethyltetracontane & 61607 & 8.12 & 605159 & $55162-61-3$ \\
\hline
\end{tabular}

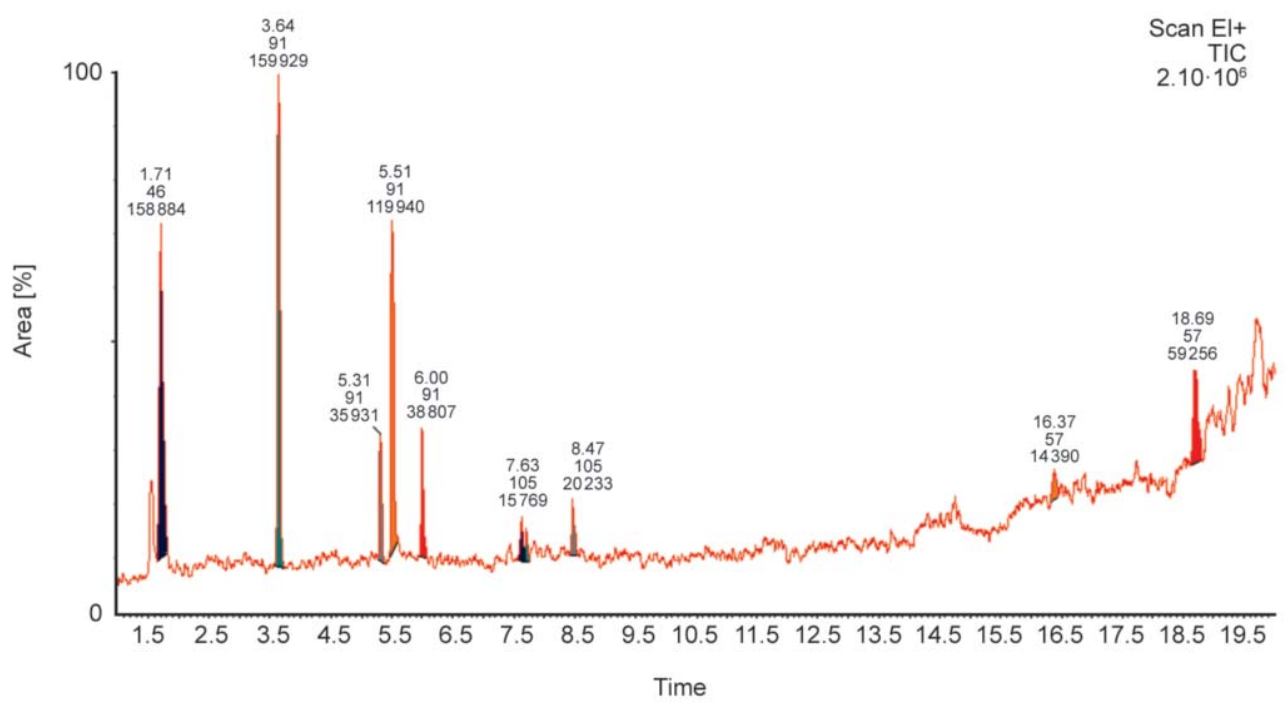

Figure 8. Chromatogram of leather seats.

Gas chromatography analysis identified the main substances from materials used in interior of vehicles which contribute to the new car odor: toluene, $p$-xylene, ethylbenzene or benzene derivatives, except in carcass of air conditioner. Polypropylene is a constituent of these components, except the rubber mats. Carbon disulfide appeared with a significant propor- tion of area in rubber mats and contributed in the formation of car odors.

The ceiling liner has great representation in the interior of vehicles, containing a large surface area, and deserves special attention. It is noteworthy that toluene, ethylbenzene and $p$-xylene featured in the peak area have odorant characteristics of pleasantness. 
The 3-carene was the substance found in a major proportion in shelf package, made from a composite of polypropylene and wood fiber. With a sweet and intense characteristic, 3-carene can be considered a material that participates in a significant way in the formation of the odor.

\section{References}

[1] Rajesh S., Ramnath B. V., Elanchezhian C., Chowdhury A., Sathya A., Deepak K. R.: Review on testing of polymer fasteners. Materials Today: Proceedings, 5, 1817 1823 (2018).

https://doi.org/10.1016/j.matpr.2017.11.280

[2] Chavez R., Sharma M.: Profitability and environmental friendliness of a closed-loop supply chain for PET components: A case study of the Mexican automobile market. Resources, Conservation and Recycling, 135, 172 189 (2018). https://doi.org/10.1016/j.resconrec.2017.10.038

[3] Wu J., Jiang F., Song H., Liu C., Lu B.: Analysis and validation of transient thermal model for automobile cabin. Applied Thermal Engineering, 122, 91-102 (2017). https://doi.org/10.1016/j.applthermaleng.2017.03.084

[4] Yoshida T., Matsunaga I., Tomioka K., Kumagai S.: Interior air pollution in automotive cabins by volatile organic compounds diffusing from interior materials: I. Survey of 101 types of Japanese domestically produced cars for private use. Indoor and Built Environment, 15, 425-444 (2006).

https://doi.org/10.1177/1420326X06069395

[5] Chien Y-C.: Variations in amounts and potential sources of volatile organic chemicals in new cars. Science of the Total Environment, 382, 228-239 (2007).

https://doi.org/10.1016/j.scitotenv.2007.04.022

[6] Chang C-T., Chen B-Y.: Toxicity assessment of volatile organic compounds and polycyclic aromatic hydrocarbons in motorcycle exhaust. Journal of Hazardous Materials, 153, 1262-1269 (2008).

https://doi.org/10.1016/j.jhazmat.2007.09.091

[7] Geiss O., Tirendi S., Barrero-Moreno J., Kotzias D.: Investigation of volatile organic compounds and phthalates present in the cabin air of used private cars. Environment International, 35, 1188-1195 (2009).

https://doi.org/10.1016/j.envint.2009.07.016

[8] Faber J., Brodzik K., Golda-Kopek A., Lomankiewicz D.: Air pollution in new vehicles as a result of VOC emissions from interior materials. Polish Journal of Environmental Studies, 22, 1701-1709 (2013).

[9] Brodzik K., Faber J., Lomankiewicz D., Gołda-Kopek A.: In-vehicle VOCs composition of unconditioned, newly produced cars. Journal of Environmental Sciences, 26, 1052-1061 (2014).

https://doi.org/10.1016/S1001-0742(13)60459-3
[10] Chen X., Feng L., Luo H., Cheng H.: Analyses on influencing factors of airborne VOCs pollution in taxi cabins. Environmental Science and Pollution Research, 21, 12868-12882 (2014). https://doi.org/10.1007/s11356-014-3223-y

[11] Lu Y-Y., Lin Y., Zhang H., Ding D., Sun X., Huang Q., Lin L., Chen Y-J., Chi Y-L., Dong S.: Evaluation of volatile organic compounds and carbonyl compounds present in the cabins of newly produced, medium- and large-size coaches in China. International Journal of Environmental Research Public Health, 13, 596-611 (2016). https://doi.org/10.3390/ijerph13060596

[12] Xu B., Chen X., Xiong J.: Air quality inside motor vehicles'cabins: A review. Indoor and Built Environment, 27, 452-465 (2018). https://doi.org/10.1177/1420326X16679217

[13] Courgneau C., Rusu D., Henneuse C., Ducruet V., Lacrampe M-F., Krawczak P.: Characterisation of lowodour emissive polylactide/cellulose fibre biocomposites for car interior. Express Polymer Letters, 7, 787804 (2013).

https://doi.org/10.3144/expresspolymlett.2013.76

[14] Corrêa C. L., Pedroso R. C.: Headspace gas chromatography with capillary column for urine alcohol determination. Journal of Chromatography B: Biomedical Sciences and Applications, 704, 365-368 (1997). https://doi.org/10.1016/S0378-4347(97)00445-3

[15] Kolb B.: Headspace sampling with capillary columns. Journal of Chromatography A, 842, 163-205 (1999). https://doi.org/10.1016/S0021-9673(99)00073-4

[16] Skoog D. A., Leary J. J.: High-performance liquid chromatography In: Principles of instrumental analysis. Harcourt Brace College Publishers, Miami (1992).

[17] Delincée H., Pool-Zobel B-L.: Genotoxic properties of 2-dodecylcyclobutanone, a compound formed on irradiation of food containing fat. Radiation Physics and Chemistry, 52, 39-42 (1998). https://doi.org/10.1016/S0969-806X(98)00070-X

[18] Zhu Y., Jin K., Li H., Qian H., Wang H., Zhao L.: A novel anode with anticorrosive coating for efficient degradation of toluene. Chemical Engineering Journal, 334, 206-215 (2018). https://doi.org/10.1016/j.cej.2017.10.048

[19] Araki A., Kawai T., Eitaki Y., Kanazawa A., Morimoto K., Nakayama K., Shibata E., Tanaka M., Takigawa T., Yoshimura T., Chikara H., Saijo Y., Kishi R.: Relationship between selected indoor volatile organic compounds, so-called microbial VOC, and the prevalence of mucous membrane symptoms in single family homes. Science of the Total Environment, 408, 2208-2215 (2010). https://doi.org/10.1016/j.scitotenv.2010.02.012 
[20] Chen X., Feng L., Luo H., Cheng H.: Health risk equations and risk assessment of airborne benzene homologues exposure to drivers and passengers in taxi cabins. Environmental Science and Pollution Research, 23, 4797-4811 (2016).

https://doi.org/10.1007/s11356-015-5678-x

[21] Hasan N. H., Said M., Leman A.: Health effect from volatile organic compounds and useful tools for future prevention: A review. International Journal of Environmental Engineering Science and Technology Research, 1, 28-36 (2013).

[22] Bowen S. E., Hannigan J. H., Davidson C. J., Callan S. P.: Abstinence following toluene exposure increases anxiety-like behavior in mice. Neurotoxicology and Teratology, 65, 42-50 (2018).

https://doi.org/10.1016/j.ntt.2017.12.010

[23] Anderson R. J., Garza H. R. M. D., Garriott J. C., Dimaio V.: Intravenous propylhexedrine (Benzedrex ${ }^{\circledR}$ ) abuse and sudden death. The American Journal of Medicine, 67, 15-20 (1979).

https://doi.org/10.1016/0002-9343(79)90063-9

[24] Corredor J. A. G., Sarria Villa R. A.: Obtención de Colofonia y Trementina a partir de resina de pino de la espécie patula y posterior evaluación de los parámetros de calidad (in Spanish). Jornal da Ciencia e Ingenieria, 5, 88-91 (2013).
[25] Ba V. A. P., Cho D-G., Kim D., Yoo H., Ta V-T., Hong S.: Quantitative electrophysiological monitoring of anti-histamine drug effects on live cells via reusable sensor platforms. Biosensors and Bioelectronics, 94, 707-713 (2017).

https://doi.org/10.1016/j.bios.2017.03.063

[26] Khajuria V., Gupta S., Sharma N., Kumar A., Lone N. A., Khullar M., Dutt P., Sharma P. R., Bhagat A., Ahmed Z.: Anti-inflammatory potential of hentriacontane in LPS stimulated RAW 264.7 cells and mice model. Biomedicine and Pharmacotherapy, 92, 175-186 (2017). https://doi.org/10.1016/j.biopha.2017.05.063

[27] Jiang Y., Li H-Y., Li X-H., Lu J., Zhang Q., Bai C. G., Chen Y.: Therapeutic effects of isothiocyanate prodrugs on rheumatoid arthritis. Bioorganic and Medicinal Chemistry Letters, 28, 737-741 (2018). https://doi.org/10.1016/j.bmcl.2018.01.009

[28] Venet T., Carreres-Pons M., Chalansonnet M., Thomas A., Merlen L., Nunge H., Bonfanti E., Cosnier F., Llorens J., Campo P.: Continuous exposure to low-frequency noise and carbon disulfide: Combined effects on hearing. Neuro Toxicology, 62, 151-161 (2017). https://doi.org/10.1016/j.neuro.2017.06.013

[29] Broda J., Gawlowski A., Slusarczyk C., Wlochowicz A., Fabia J.: The influence of additives on the structure of polypropylene fibres. Dyes and Pigments, 74, 508511 (2007). https://doi.org/10.1016/j.dyepig.2006.10.004 